\title{
Production performances and antioxidant activities of laying hens fed Aspergillus oryzae and phytase co-fermented wheat bran
}

\author{
Chung Ming Huang ${ }^{1}$, Wen Yang Chuang ${ }^{1}$, Wei Chih Lin ${ }^{1}$, Li Jen Lin², \\ Sheng Chang Chang ${ }^{3}$, and Tzu Tai Lee ${ }^{1,4, *}$
}

\section{* Corresponding Author: Tzu Tai Lee Tel: +886-4-2284-0366, Fax: +886-4-2286-0265 \\ E-mail: ttlee@dragon.nchu.edu.tw \\ 1 Department of Animal Science, National Chung Hsing University, Taichung 402, Taiwan \\ 2 School of Chinese Medicine, College of Chinese Medicine, China Medical University, Taichung 404, Taiwan \\ ${ }^{3}$ Kaohsiung Animal Propagation Station, Livestock Research Institute, Council of Agriculture, Kaohsiung 912, Taiwan \\ ${ }^{4}$ The iEGG and Animal Biotechnology Center, National Chung Hsing University, Taichung 402, Taiwan}

ORCID

Chung Ming Huang

https://orcid.org/0000-0001-7692-5542 Wen Yang Chuang

https://orcid.org/0000-0002-5282-5878 Wei Chih Lin

https://orcid.org/0000-0002-7476-5394 Li Jen Lin

https://orcid.org/0000-0001-7914-9235 Sheng Chang Chang

https://orcid.org/0000-0003-1746-9481

Tzu Tai Lee

https://orcid.org/0000-0002-0063-5714

Submitted Feb 22, 2020; Revised Mar 25, 2020 ; Accepted Apr 29, 2020
Objective: Wheat bran (WB) was co-fermented with Aspergillus oryzae and phytase (Phy) to determine whether co-fermentation improve WB phosphorus and fiber utilization in Isa-brown layers.

Methods: A total of 112 Isa brown layer were randomly divided into 7 treatments with 8 replicates per a treatment and 2 hens per a replicate. The treatments included basal diet (control), basal diet supplemented with 250 unit/kg Phy (control+Phy), diet with 10\% WB (10\% WB), diet with 5\% WB and 250 unit/kg Phy (5\% WB+Phy) diet with $10 \% \mathrm{WB}$ and 250 unit/kg Phy (10\% WB+Phy), diet with 5\% fermented WB supplemented with molasses and phy (PCFWH) and 125 unit/kg Phy (5\% PCFWH), and diet with 10\% PCFWH (10\% PCFWH). The intestinal microbial population, intestinal morphology, serum antioxidant enzyme activities, and excreta phosphorus content were assessed.

Results: In PCFWH, spore counts, protease activity, xylanase activity, and ferulic acid were $8.50 \mathrm{log} / \mathrm{g}$ dry matter (DM), $190 \mathrm{unit} / \mathrm{g} \mathrm{DM}, 120 \mathrm{unit} / \mathrm{g} \mathrm{DM}$, and $127 \mu \mathrm{g} / \mathrm{g}$, respectively. Xylobiose and xylotriose were released in PCFWH, while they were not detectable in WB. Antioxidant capacity was also enhanced in PCFWH compared to WB. The $10 \% \mathrm{WB}+\mathrm{Phy}$ and $10 \%$ PCFWH groups produced higher egg mass, but hens fed 5\% WB+Phy had the lowest amount of feed intake. Eggs from 10\% PCFWH had better eggshell weight, eggshell strength, and eggshell thickness. Birds fed with 10\% PCFWH also had higher serum superoxide dismutase and catalase activities. Compare to control, 10\% PCFWH significantly reduced excreta phosphorus content.

Conclusion: Diet inclusion of 10\% PCFWH improved egg quality, antioxidant status, and excreta phosphorus content of laying hens.

Keywords: Phytase; Aspergillus oryzae; Co-fermentation; Antioxidant; Hen

\section{INTRODUCTION}

Island states like Taiwan do not have enough land area for planting to supply poultry and livestock, so domestic animal husbandry mainly relies on imported feeds. For the poultry industry, feed cost occupy about $60 \%$ to $70 \%$ of total cost of production. However, feed prices, which are depended on international prices of cereals, fluctuates over time. Elevated feed prices may have an enormous impact on national animal husbandry. Therefore, reducing feed cost and development of agricultural by-products as alternative feedstuffs are goals of recent studies.

There are a great amount of arabinoxylans in wheat bran (WB). As arabinoxylans broken down, released xylooligosaccharides are expected to promote microbial fermentation, and raise the number of lactic acid bacteria in the intestine [1]. In order to raise digestibility and utilization of nutrients in agricultural by-products, degradation of cellulose and hemi- 
cellulose are a priority. Biological treatments include enzymatic treatments and microbial fermentation, among which solidstate fermentation (SSF) is preferred to reduce the cost. Studies found that arabinoxylans from WB possessed immunomodulatory effects in vitro [1], while a negative effect on growth performance was shown when the WB inclusion level was over $10 \%$ in the diet of broilers [2]. It has been proved that xylooligosaccharides exert prebiotic effects, improve gut health and performance of broilers [3,4]. Accordingly, SSF of WB may not only reduce the harmful effect of non-starch polysaccharides but elevate the nutritional value of substates.

Ferulic acid is commonly found in cereals [5]. In destarched WB, its content can reach $7.4 \mu \mathrm{g} / \mathrm{mg}$ [6]. Microbial enzymes were commonly used to release ferulic acid as well as feruloyl oligosaccharides (FOs) from WB dietary fiber [7]. The FOs also display great antioxidant activity in vitro and in vivo [7]. Recently, production of FOs through fermentation by Aureobasidium pullulans 2012 was studied and the yield of FOs could reach $774 \mathrm{nmol} / \mathrm{L}$ [8], and these FOs exert an antioxidant effect [8].

Phytic acid, also named as myo-inositol, 1,2,3,4,5,6-hexakisphosphate (IP6), is formed from an inositol ring linked with six phosphates. In WB, over $90 \%$ of total phosphorus was in form of phytate that could not be utilized as monogastric animals lacked endogenous phytase (Phy) [9]. Previous study indicated that Paecilomyces variotii fermented sorghum combined with Phy supplementation improved inorganic phosphorus content in sorghum, while whether the inoculated fungus could produce Phy was not assessed in this study [10]. Moreover, a combination of Phy addition with fungal fermentation was not compared to either treatment in this study [10]. Thus, to ensure its feasibility, the novel strategy for phosphorus release requires further exploration.

Aspergillus oryzae (A. oryzae) is very suitable for feed fermentation and application in animals because it can produce a tremendous amount of enzymes within short period and is categorized as Generally Recognized As Safe (GRAS) by Food and Drug Administration (GRAS Notice No. GRN 000829). Broilers fed with A. oryzae fermented soybean meal (FSBM) had improved growth performance and increased serum total phosphorus and IgM content in all growth stages compared with the soybean meal group [11]. Similar results were found in weaned piglets fed with A. oryzae FSBM [12]. Feeding FSBM improved growth performance of animals probably because the digestibility of dry matter (DM), crude protein $(\mathrm{CP})$, and amino acids as well as intestinal protease activities were enhanced [12,13]. Accordingly, A. oryzae fermented feed has potential for animal nutrition, but little research has been carried out comparing WB with A. oryzae co-fermented WB with or without Phy; therefore, this research is to reveal the effect of $A$. oryzae and pytase co-fermented WB in layers diet.

\section{MATERIALS AND METHODS}

\section{Solid-state fermentation}

The starter culture was prepared by $30 \mathrm{~g}$ soybean added to $20 \mathrm{~mL}$ deionized water, autoclaved, inoculated with $10 \mathrm{~mL}$ phosphate buffered saline containing $9 \times 10^{6}$ A. oryzae spores/ $\mathrm{mL}$, and incubated at $30^{\circ} \mathrm{C}$ for three days. The $300 \mathrm{~g} \mathrm{WB}$ was mixed with $300 \mathrm{~mL}$ deionized water and $30 \mathrm{~g}$ molasses. The mixture was autoclaved at $121^{\circ} \mathrm{C}$ for $20 \mathrm{~min}$ and inoculated with the starter culture as well as 750 unit Phy. Then, the mixture was incubated at $30^{\circ} \mathrm{C}$. At the end of fermentation, samples were stored at $-20^{\circ} \mathrm{C}$ for enzyme activities and spore counts assays. In other assays, samples were dried at $50^{\circ} \mathrm{C}$ for $24 \mathrm{~h}$, smashed, and stored at $4^{\circ} \mathrm{C}$.

\section{Extractable phosphorus}

Determination of extractable phosphorus was modified from previous study [1]. Briefly, $5 \mathrm{~g}$ of each sample were mixed with $50 \mathrm{~mL} 0.2 \%$ pepsin solution, which was prepared with $0.2 \mathrm{~g}$ pepsin (Sigma, St. Louis, MO, USA) dissolved in $100 \mathrm{~mL}$ $0.1 \mathrm{M} \mathrm{HCl}$ solution. After $3 \mathrm{~h}$ of incubation at $37^{\circ} \mathrm{C}$ and 80 $\mathrm{rpm}$, the mixtures were centrifuged at 3,000 rpm, followed by filtration through Advantec No.1 filter papers. The $0.3 \mathrm{~mL}$ extracts were added to $0.6 \mathrm{~mL}$ deionized water and $0.6 \mathrm{~mL}$ vanadium-ammonium molybdate solution, which was prepared with nitric acid, ammonium metavanadate (Sigma, USA) and ammonium molybdate tetrahydrate (Sigma, USA). Then, the mixtures were centrifuged again at 6,000 rpm for $10 \mathrm{~min}$, and the absorbance of suspension was detected at $415 \mathrm{~nm}$. Solutions of 0.3125 to $2.5 \mu \mathrm{mol} / \mathrm{mL}$ potassium dihydrogen phosphate were also detected to draw a standard curve. The $300 \mathrm{~g} \mathrm{WB}$ treated with 750-unit Phy was also analyzed.

\section{2,2-Diphenyl-1-picrylhydrazyl scavenging activity}

This assay was conducted according to previous report [14]. Samples and reagents were prepared with ethanol as the solvent. Samples were added to ethanol and vibrated for $30 \mathrm{~min}$ in ice bath. Mixtures were filtrated through Advantec No.1 filter paper. The filtrates were mixed with $1 \mathrm{mM}$ 2,2-diphenyl1-picrylhydrazyl (DPPH) at the ratio of 4:1, and protected from light for $30 \mathrm{~min}$. Then, solutions were centrifuged at $8,000 \times \mathrm{g}$ for $5 \mathrm{~min}$, and suspensions were detected at $517 \mathrm{~nm}$. Scavenging rate of DPPH was calculated by the following equation:

\section{Scavenging rate

$$
=1-\frac{\text { absorbance of samples at } 517 \mathrm{~nm}}{\text { absorbance of control group at } 517 \mathrm{~nm}}
$$

where ethanol was used as the control group, and butylated hydroxytoluene (BHT) was as the positive control. 


\section{2,2-azino-bis (3-ethyl-benzthiazoline-6-sulfonic acid) scavenging activity}

The method was according to previous research [15]. Sample extraction steps were as same as in the analysis of total phenol content. The reagent was prepared with 4.4 unit $/ \mathrm{mL}$ peroxidase, $100 \mu \mathrm{M}$ 2,2-azino-bis (3-ethyl-benzthiazoline6-sulfonic acid) (ABTS), and deionized water at the ratio of 1:1:6. Next, $0.1 \mathrm{~mL}$ extracts were mixed with $0.9 \mathrm{~mL}$ reagent, reacting at room temperature for $10 \mathrm{~min}$. The absorbance was monitored at $734 \mathrm{~nm}$, and ABTS scavenging rate was calculated using the following equation:

\section{Scavenging rate $=1-\frac{\text { absorbance of samples at } 734 \mathrm{~nm}}{\text { absorbance of control group at } 734 \mathrm{~nm}}$}

where deionized water was the control group, and vitamin C was as the positive control.

\section{Xylooligosaccharides}

Xylooligosaccharides content was determined by high performance liquid chromatography (HITACHI, Kyoto, Japan) equipped with the pump (L-2130) and the RI-detector (L2490), according to the method already set up in our laboratory [1]. Briefly, $5 \mathrm{~g}$ of each sample were mixed with $50 \mathrm{~mL}$ deionized water, and vortexed in $95^{\circ} \mathrm{C}$ baths for $1 \mathrm{~h}$. The extracts were centrifuged at 3,000 rpm for $10 \mathrm{~min}$. The suspensions were further filtrated through $0.22 \mu \mathrm{m}$ filter paper. The temperature of column (Transgenomic CARBOSep CH0682 $\mathrm{Pb}, 300 \mathrm{~mm} \times 7.8 \mathrm{~mm}$ ) was maintained at $80^{\circ} \mathrm{C}$. Doubly deionized water was applied as mobile phase, and the flow rate was set at $0.4 \mathrm{~mL} / \mathrm{min}$. The standards, including $\mathrm{D}$ - $\mathrm{xy}$ lose, xylobiose, xylotriose, xylotetraose, xylopentaose, and xylohexatiose, were diluted into 0.2 to $1 \mathrm{mg} / \mathrm{mL}$ for calibration.

\section{Experimental design}

This experiment is conducted at National Chung Hsing University, Taiwan. All of the protocols for animal use were approved by the Animal Care and Use Committee (IACUC: 107-013). One hundred and twelve Isa-brown laying hens were randomly assigned to 7 treatments with 8 replicates per treatment and two hens per replicate in an individual cage $(35 \times 40 \times 40 \mathrm{~cm})$. Hens were in a house equipped with wet pad cooling system, and the temperature was controlled below $30^{\circ} \mathrm{C}$. The experimental diets were fed to 29 - to 40 -week-old laying hens. Crumble diets and water were fed ad libitum. The illumination plan was conducted as $15.5 \mathrm{~h}$ of light and $8.5 \mathrm{~h}$ of darkness per day. The maize-soybean meal basal diets fed to birds were formulated to meet recommended nutrient requirements (NRC, 1994). In the first part of experiment, WB and fermented WB supplemented with molasses and phy
(PCFWH) were incorporated into the diets as partial replacement for maize and soybean meal. Seven dietary treatments were as followed: basal diet (control), basal diet supplemented with 250 unit $/ \mathrm{kg}$ Phy (control+Phy), diet with $10 \%$ WB (10\% WB), diet with 5\% WB and 250 unit $/ \mathrm{kg}$ Phy (5\% WB+Phy) diet with $10 \% \mathrm{WB}$ and 250 unit/kg Phy (10\% WB+Phy), diet with 5\% PCFWH and 125 unit/kg Phy (5\% PCFWH), and diet with 10\% PCFWH (10\% PCFWH). In order to equal the amount of Phy added into the diets, it was noted that 125 unit/kg Phy was added into diet with 5\% PCFWH, in which Phy (250 unit/100 g WB) has been already added into PCFWH at the moment when starter culture was added. The nutrient compositions of experimental diets are shown in Table 1.

\section{Performance, egg production, serum, and intestinal content collection}

Performance of laying hens was measured from 29- to 40-wkold hens. Eggs weight and laying rate were recorded daily. Eggs from each replicate were collected weekly and stored at $4^{\circ} \mathrm{C}$ for egg quality analysis. To avoid sampling interfering with laying hen performance, other analyses were done after the record of performance was ended. Blood samples were collected at 10 a.m. from the brachial wing vein of each replicate ( 8 birds per treatment) using a vacuum blood collection tube. Blood samples were stored at room temperature for coagulation, and then centrifuged at 3,000 rpm for $15 \mathrm{~min}$. The serum was loaded into eppendorf tubes and stored at $-20^{\circ} \mathrm{C}$ for further analysis. For intestinal microbial population, birds were electrically stunned and dissected. Ileal and cecum contents were collected in sterilized dishes for following analysis.

\section{Egg quality}

The egg quality was measured according to the method described by Lin et al [16]. Briefly, egg weight, eggshell strength, height of thick albumen, and yolk color were analyzed by the machine (DET 6000, NABEL Co., Ltd., Kyoto, Japan). The Haugh unit was calculated using Haugh unit formula in which height of thick albumen and egg weight were parameters. The thickness of middle section of eggshell was measured, while eggshell membrane was excluded from the shell before measurement.

\section{Intestinal microbial population}

One gram of ileal and cecum contents was weighed, and serially diluted with sterilized PBS. Diluted samples were loaded on chromogenic medium agar (CHROMagarTM 129 ECC) and MRS medium (de Man Rogosa and Sharpe agar, Difco 288130, BD, Franklin Lakes, NJ, USA) plates for determining the population of coliform and lactic acid bacteria. The inoculated chromogenic medium plates were incubated at 
Table 1. Ingredients and chemical composition of the experimental diets for laying hens

\begin{tabular}{|c|c|c|c|c|c|c|c|}
\hline Items & Control $^{1)}$ & $10 \%$ WB & Control+Phy & $5 \%$ WB+Phy & $10 \%$ WB+Phy & 5\% PCFWH & $10 \%$ PCFWH \\
\hline \multicolumn{8}{|l|}{ Ingredients (g/kg) } \\
\hline Corn & 570.0 & 470.9 & 570.0 & 524.6 & 470.9 & 536.0 & 498.4 \\
\hline Soybean meal, CP 44\% & 216.0 & 134.0 & 216.0 & 180.0 & 134.0 & 170.9 & 97.8 \\
\hline WB & 0 & 100.0 & 0 & 50.0 & 100.0 & 0 & 0 \\
\hline PCFWH & 0 & 0 & 0 & 0 & 0 & 50.0 & 100.0 \\
\hline Phytase, unit & 0 & 0 & 250 & 250 & 250 & 125 & 0 \\
\hline Full fat soybean meal & 12.0 & 95.0 & 12.0 & 52.3 & 95.0 & 50.0 & 110.7 \\
\hline Soybean oil & 20.0 & 33.0 & 20.0 & 26.0 & 33.0 & 26.0 & 26.0 \\
\hline Limestone & 73.0 & 73.0 & 73.0 & 73.0 & 73.0 & 73.0 & 73.0 \\
\hline Dicalcium phosphate & 26.0 & 26.0 & 26.0 & 26.0 & 26.0 & 26.0 & 26.0 \\
\hline DL-methionine & 1.30 & 1.30 & 1.30 & 1.30 & 1.30 & 1.30 & 1.30 \\
\hline Total & 1,000 & 1,000 & 1,000 & 1,000 & 1,000 & 1,000 & 1,000 \\
\hline \multicolumn{8}{|l|}{ Calculated nutrient value } \\
\hline ME (kcal/kg) & 2,850 & 2,850 & 2,850 & 2,850 & 2,850 & 2,850 & 2,850 \\
\hline Dry matter (\%) & 88.5 & 89.0 & 88.5 & 88.8 & 89.0 & 89.1 & 89.7 \\
\hline Crude protein (\%) & 18.0 & 18.0 & 18.0 & 18.0 & 18.0 & 18.0 & 18.0 \\
\hline Crude fat (\%) & 5.58 & 8.12 & 5.58 & 6.73 & 8.12 & 6.76 & 7.85 \\
\hline Calcium (\%) & 3.56 & 3.58 & 3.56 & 3.57 & 3.58 & 3.57 & 3.57 \\
\hline Total phosphorus (\%) & 0.86 & 0.91 & 0.86 & 0.88 & 0.91 & 0.88 & 0.90 \\
\hline Available phosphorus (\%) & 0.68 & 0.70 & 0.68 & 0.66 & 0.70 & 0.66 & 0.66 \\
\hline Lysine (\%) & 0.93 & 0.98 & 0.93 & 0.97 & 0.98 & 0.94 & 0.93 \\
\hline Methionine (\%) & 0.46 & 0.46 & 0.46 & 0.46 & 0.46 & 0.45 & 0.45 \\
\hline
\end{tabular}

WB, wheat bran; Phy, WB added with phytase; PCFWH, fermented WB supplemented with molasses and phytase; CP, crude protein; DDGS, dry distillers grains with solubles; ME, metabolizable energy.

1) Control, basal diet; 10\% WB, diet with 10\% WB; Control+Phy, basal diet supplemented with 250 unit/kg phytase; 5\% WB+Phy, diet with 5\% WB and 250 unit/kg phytase; 10\% WB+Phy, diet with 10\% WB and 250 unit/kg phytase; 5\% PCFWH, diet with 5\% PCFWH and 125 unit/kg phytase; 10\% PCFWH, diet with $10 \%$ PCFWH.

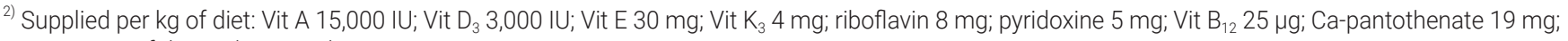
niacin $50 \mathrm{mg}$; folic acid $1.5 \mathrm{mg}$; biotin $60 \mu \mathrm{g}$.

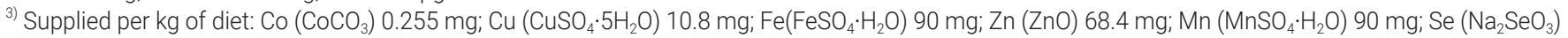
$0.18 \mathrm{mg}$.

4) The activities unit of phytase presented by phytase unit (FTU) per kg feed and the activities of phytase was estimated according to the addition amount and research of Okot-Kotber et al [17].

$37^{\circ} \mathrm{C}$ for $24 \mathrm{~h}$, and MRS plates were incubated for $48 \mathrm{~h}$. Colonies were counted and expressed as Log colony-forming unit/g of intestinal contents in four replicates.

\section{Intestinal morphology}

After performance recording ended, hens were sacrificed by exsanguination from the jugular vein. Next, birds were dissected, and the intestines were carefully removed. Middle part of jejunum and ileum were cut out, put into the forma- lin, and stored at room temperature for at least one week for fixation. Fixed intestinal sections were stained using hematoxylin and eosin staining methods. The villus height, crypt depth, and the ratio of villus height to crypt depth were measured by optical microscope connected to computer software (Motic image plus 2.0, Richmond, Canada). Intestinal morphology was measured in four replicates, and ten intestinal villi and crypts per replicate were measured. 


\section{Serum antioxidant enzymes}

The superoxidase dismutase (SOD), catalase (CAT), and thiobarbituric acid reactive substances assay kits (Cayman Chemical Co., Ltd., Ann Arbor, MI, USA) were applied for determination of SOD activity, CAT activity, and total malondialdehyde (MDA) in serum samples. Serum samples were assessed in sextuplicate per treatment.

\section{Excreta phosphorus contents}

After the record of performance and production ended, clean plastic panels were put at the bottom of cages for excreta collection. One day later, excreta from each treatment was sampled and stored at $-20^{\circ} \mathrm{C}$. One gram of excreta samples were put in crucibles and incinerated at $600^{\circ} \mathrm{C}$ for $6 \mathrm{~h}$. After crucibles cooled down, $10 \mathrm{~mL} 3 \mathrm{~N} \mathrm{HCl}$ was added, and boiled for at least $10 \mathrm{~min}$. Then, solutions were filtrated, and quantified to $50 \mathrm{~mL}$. The phosphorus content in the excreta was analyzed with molybdovanadate reagent, and different concentrations of monopotassium phosphate were prepared as standards. All treatments were analyzed in four replicates.

\section{Statistical analyses}

Data were analyzed for significance by analysis of one-way variance and general linear model procedure of using SAS software (SAS 9.4, 2018) program. The mean value is shown in tables and figures and determination of significant differences between treatment groups was conducted using Tukey tests with p-value less than 0.05 . The mathematic model was shown as follow:

$$
Y_{i j}=\mu+T_{i}+\varepsilon_{i j}
$$

where $Y_{i j}=$ results in each pen; $\mu$ = overall mean; $T_{i}=$ fixed effect of WB, Phy, and PCFWH supplementation; and $\varepsilon_{i j}=$ residual error when a pen was consider to be experimental unit, $\varepsilon_{i j} \sim N\left(0, \sigma_{\varepsilon}^{2}\right)$

\section{RESULTS}

\section{$\mathrm{WB}$ and PCFWH characteristics}

In the proximate analysis shown in Table 2 , the $\mathrm{CP}$, neutral detergent fiber (NDF), acid detergent fiber (ADF), and ether extract (EE) were $17.5 \%, 37.6 \%, 7.64 \%$, and $4.35 \%$ in $\mathrm{WB}$, respectively. After fermentation by A. oryzae, the $\mathrm{CP}, \mathrm{ADF}$, and $\mathrm{EE}$ content raised to $25.8 \%, 8.35 \%$, and $5.13 \%$, respectively, while NDF content decreased to $33.0 \%$ on the DM basis. Metabolites of A. oryzae, including spore counts, enzyme activities, and ferulic acid contents, are shown in Table 2. In WB, spore counts of A. oryzae, protease, and xylanase activities were not determined, while they were $8.5 \mathrm{log} / \mathrm{g} \mathrm{DM}$, 190 unit/g DM, and 120 unit/g DM in PCFWH, respectively. The ferulic acid contents were also measured. In PCFWH,
Table 2. Proximate analysis of wheat bran and fermented wheat bran supplemented with molasses and phytase

\begin{tabular}{lcc}
\hline Items & WB & PCFWH \\
\hline $\mathrm{DM}$ & $88.1 \pm 0.20$ & $94.8 \pm 0.13$ \\
$\mathrm{CP}(\% \mathrm{DM})$ & $17.5 \pm 0.53$ & $25.8 \pm 0.67$ \\
$\mathrm{NDF}(\% \mathrm{DM})$ & $37.6 \pm 0.74$ & $33.0 \pm 0.41$ \\
$\mathrm{ADF}(\% \mathrm{DM})$ & $7.64 \pm 0.17$ & $8.35 \pm 0.35$ \\
$\mathrm{EE}(\% \mathrm{DM})$ & $4.35 \pm 0.82$ & $5.13 \pm 0.09$ \\
Ash $(\% \mathrm{DM})$ & $5.11 \pm 0.31$ & $6.97 \pm 0.05$ \\
Spore counts $(\mathrm{log} / \mathrm{g} \mathrm{DM})$ & $\mathrm{ND}$ & $8.50 \pm 0.27$ \\
Protease $(\mathrm{unit} / \mathrm{g} \mathrm{DM})^{1)}$ & $\mathrm{ND}$ & $190 \pm 16.4$ \\
Xylanase $(\mathrm{unit} / \mathrm{g} \mathrm{DM})^{2)}$ & $\mathrm{ND}$ & $120 \pm 13.9$ \\
Ferulic acid $(\mu \mathrm{g} / \mathrm{g})$ & $29.0 \pm 12.4$ & $127 \pm 23.1$ \\
D-xylose $(\mathrm{mg} / \mathrm{g})$ & $\mathrm{ND}$ & $9.98 \pm 0.50$ \\
Xylobiose $(\mathrm{mg} / \mathrm{g})$ & $\mathrm{ND}$ & $3.78 \pm 0.21$ \\
Xylotriose $(\mathrm{mg} / \mathrm{g})$ & $\mathrm{ND}$ & $14.0 \pm 0.84$ \\
\hline
\end{tabular}

All data are expressed as means \pm standard deviation from three replicates $(n=3)$.

WB, wheat bran; PCFWH, fermented WB supplemented with molasses and phytase; $\mathrm{DM}$, dry matter; $\mathrm{CP}$, crude protein; NDF, neutral detergent fiber; ADF, acid detergent fiber; EE, ether extract; ND, not determined.

1) One unit of protease activity is defined as $1 \mu \mathrm{g}$ L-tyrosine is generated from $10 \mathrm{mg} / \mathrm{mL}$ casein in the condition of $40^{\circ} \mathrm{C}$ and $\mathrm{pH} 7.5$ in a minute.

2) One unit of xylanase activity is defined as $1 \mu \mathrm{mol} \mathrm{D}$-xylose is generated from $10 \mathrm{mg} / \mathrm{mL}$ xylan in the condition of $37^{\circ} \mathrm{C}$ and $\mathrm{pH} 5.5$ in a minute.

the ferulic acid content was almost four-fold higher than that in WB (127 vs $29.0 \mu \mathrm{g} / \mathrm{g}$ ). Results of the tyrosinase inhibition rate are shown in Table 2. Kojic acid was the tyrosinase inhibitor, so it was used as positive control. The concentrations of all examined treatments were $100 \mathrm{mg} / \mathrm{mL}$. The tyrosinase inhibition rate of WB was not detectable, while it was $6.04 \%$ and $97.2 \%$ in PCFWH and kojic acid, respectively. Results of xylooligosaccharides contents are illustrated in Figure 1 and quantified in Table 2. All xylooligosaccharides and D-xylose were not detectable in WB. In PCFWH, D-xylose, xylobiose, and xylotriose were $9.98,3.78$, and $14.0 \mathrm{mg} / \mathrm{g}$, respectively, while the xylotetraose, xylopentaose, and xylohexaose were not detectable.

The extractable phosphorus was determined in acidic solutions to simulate the gastric environment and shown in Figure 2. Results demonstrated that WB rarely released inorganic phosphorus $(5.09 \mu \mathrm{mol} / \mathrm{g} \mathrm{DM})$, while FWBM group had significantly enhanced inorganic phosphorus content $(77.6 \mu \mathrm{mol} / \mathrm{g} \mathrm{DM})$. The WB added with Phy released 218 $\mu \mathrm{mol} / \mathrm{g}$ DM phosphorus. Aspergillus oryzae fermented WB combined with Phy addition (PCFWH) promoted much more inorganic phosphorus $(290 \mu \mathrm{mol} / \mathrm{g} \mathrm{DM})$.

Results of in vitro antioxidant assays are illustrated in Figure 3 (A and $\mathrm{B}$ ). The DPPH scavenging rate (Figure $3 \mathrm{~A}$ ) was $26.0 \%$ in PCFWH compared to $7.07 \%$ in $\mathrm{WB}$ at the concentration of $1 \mathrm{mg} / \mathrm{mL}$. As the concentrations reached to $10 \mathrm{mg} / \mathrm{mL}$, the DPPH scavenging rate of PCFWH was close to the result of BHT (94.5\%) and was $41.9 \%$ higher than that of WB group (93.8\% vs 51.9\%). The ABTS scavenging 

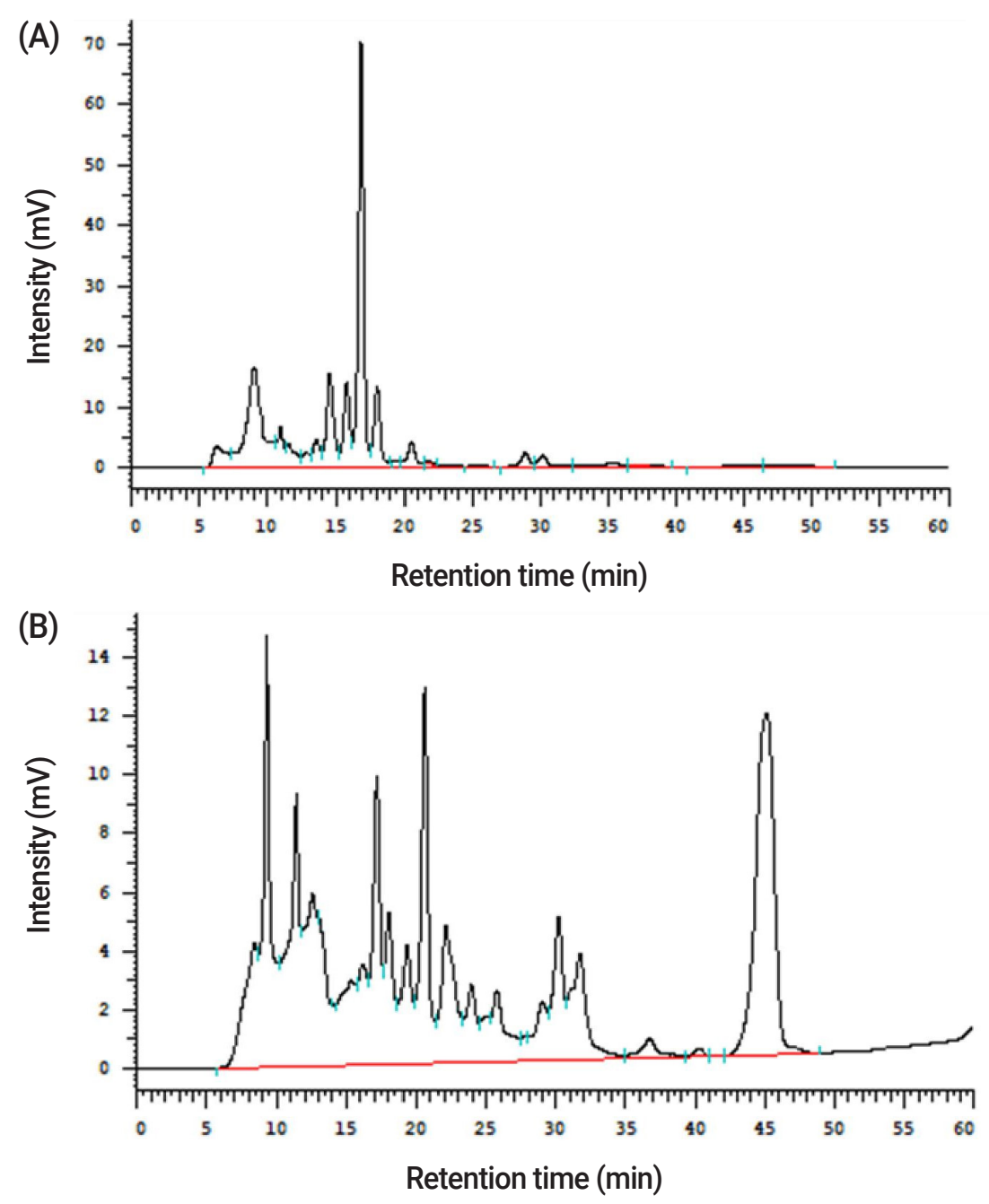

Figure 1. Xylooligosaccharides contents in (A) WB, and (B) PCFWH determined by high performance liquid chromatography. WB, wheat bran; PCFWH, fermented WB supplemented with molasses and phytase.

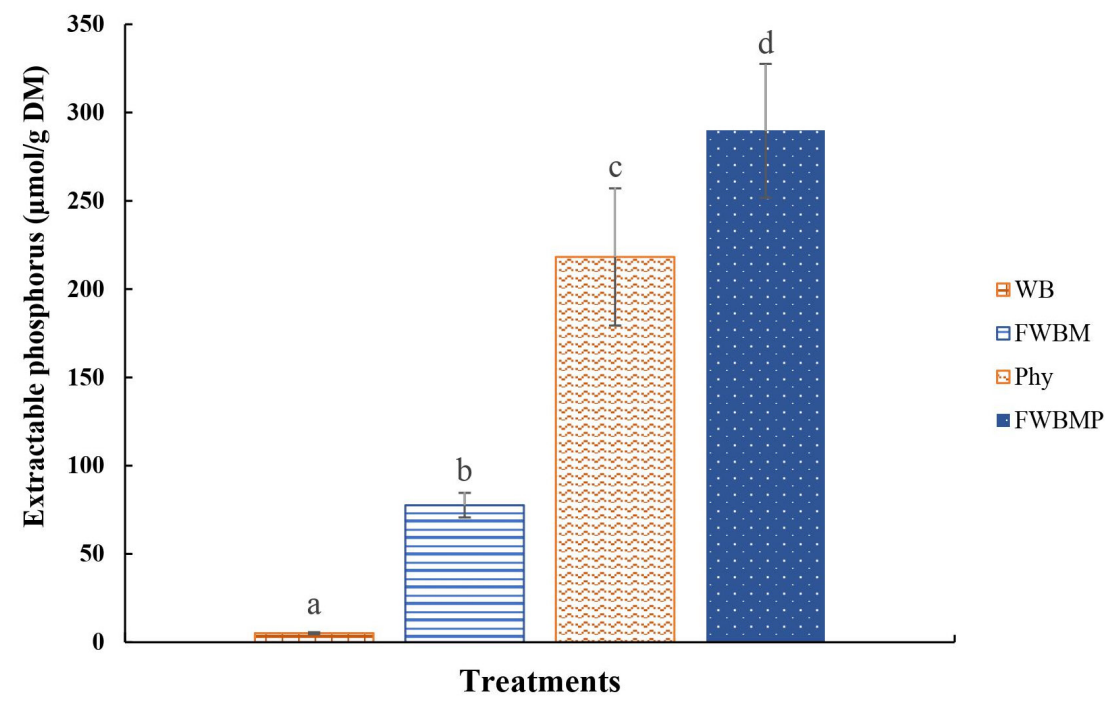

Figure 2. The extractable phosphorus ( $\mu \mathrm{mol} / \mathrm{g}$ dry matter) of WB with different treatments. WB, wheat bran; FWBM, fermented WB added with molasses; Phy, WB added with phytase; PCFWH, fermented WB supplemented with molasses and phytase. Each value represents the mean \pm tandard deviation of three replicates $(n=3)$. ${ }^{\text {a-d }}$ Means with different letters are significantly different $(p<0.05)$. 
rate (Figure $3 \mathrm{~B}$ ) was $9.85 \%$ to $51.4 \%$ at the concentrations of 10 to $80 \mathrm{mg} / \mathrm{mL}$ in $\mathrm{WB}$, while it was $31.5 \%$ to $76.6 \%$ at the concentrations of 10 to $80 \mathrm{mg} / \mathrm{mL}$ in PCFWH.

\section{Layer performance and egg quality}

Results of performance and production of laying hens from 1 to $12 \mathrm{wk}$ are demonstrated in Table 3. The lowest feed intake was observed in $5 \% \mathrm{WB}+\mathrm{Phy}(\mathrm{p}<0.05)$, while there was no significant difference between other treatments. The lower egg mass was found in treatments of control and $5 \% \mathrm{WB}+\mathrm{Phy}$. In the results of laying rate and feed conversion ratio (FCR), no significant differences were found between treatments.

The results of egg quality analysis are shown in Table 4 . The egg weight of $10 \% \mathrm{WB}+$ Phy was significantly higher than that of control, $10 \% \mathrm{WB}$, control+Phy, and $5 \% \mathrm{WB}+\mathrm{Phy}$. Results demonstrated that eggs of $10 \%$ PCFWH had significantly better egg quality regarding the eggshell weight, eggshell strength, and eggshell thickness $(\mathrm{p}<0.001)$, while control and $10 \%$ PCFWH resulted in the lowest value of yolk color compared to other treatments $(p=0.001)$. The heaviest egg weight occurred in $10 \mathrm{WB}+\mathrm{Phy}$, but the eggshell strength in this treatment was the weakest. The thinnest shell thickness was

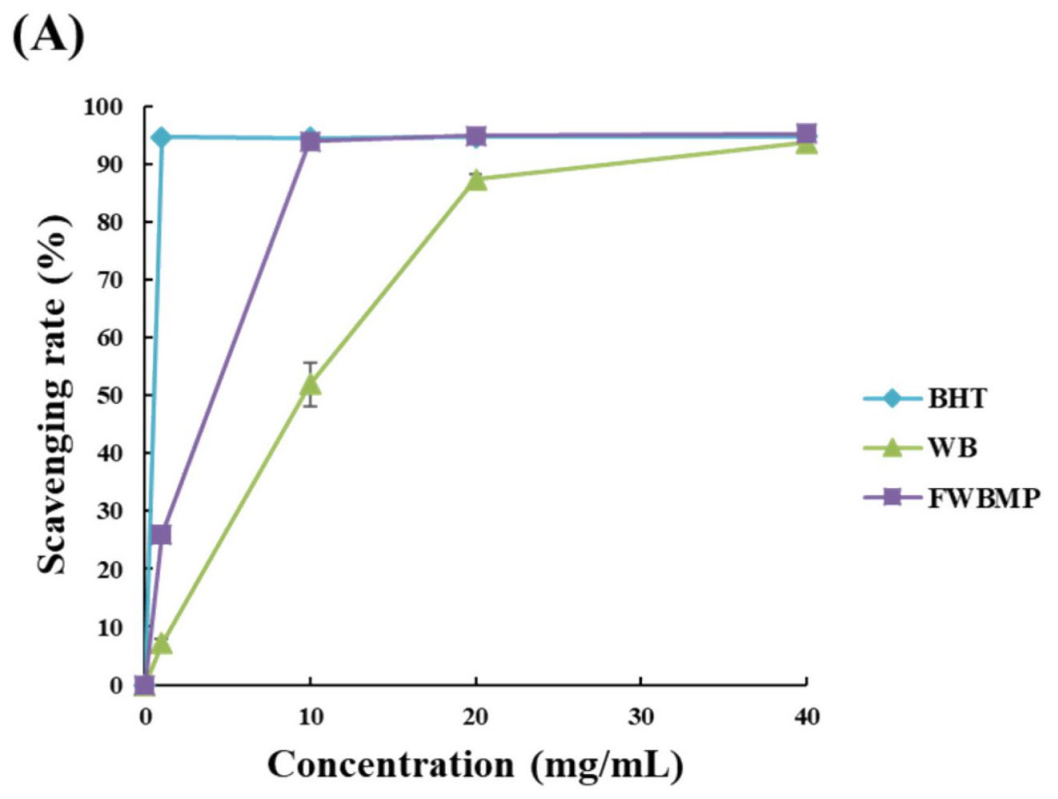

(B)

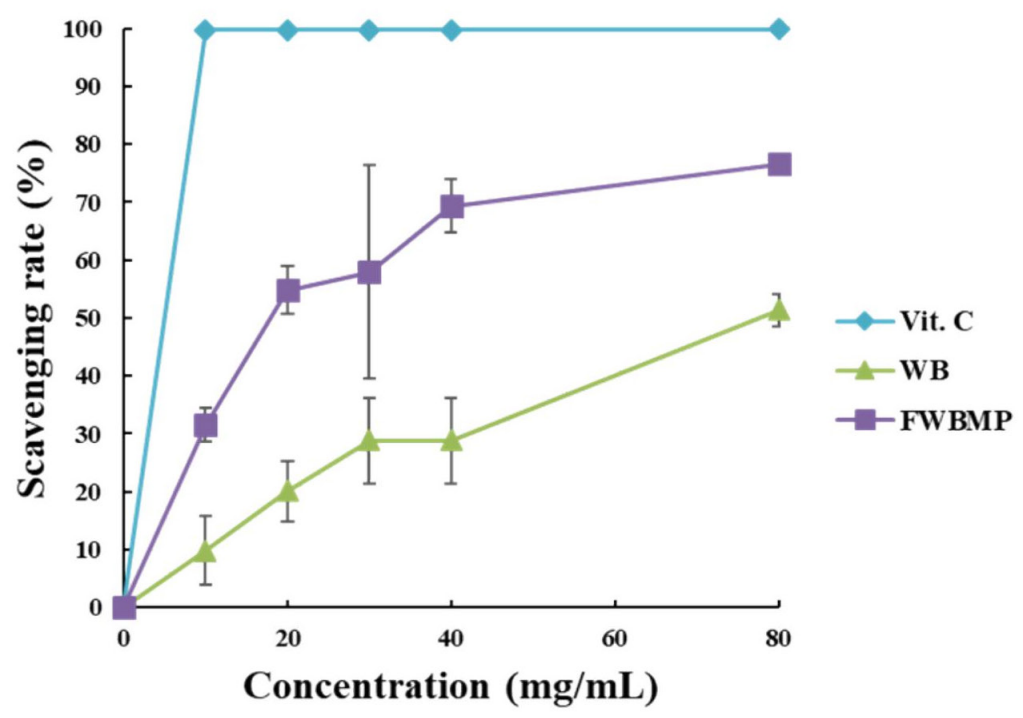

Figure 3. The antioxidant capacity of WB, and PCFWH at different concentrations ( $\mathrm{mg} / \mathrm{mL}$ ) are presented as (A) 2,2-diphenyl-1-picrylhydrazyl, and (B) 2,2-azino-bis [3-ethyl-benzthiazoline-6-sulfonic acid] scavenging rate. WB, wheat bran; PCFWH, fermented WB supplemented with molasses and phytase; BHT, butylated hydroxytoluene. Each value represents the meantstandard deviation of three replicates $(n=3)$. 
Table 3. Effects of experimental diets on the performance and production of laying hens from 1 to $12 \mathrm{wk}$

\begin{tabular}{|c|c|c|c|c|c|c|c|c|c|}
\hline \multirow{2}{*}{ Items } & \multicolumn{7}{|c|}{ Experimental diets $^{1)}$} & \multirow{2}{*}{ SEM } & \multirow{2}{*}{ p-values } \\
\hline & Control & $10 \%$ WB & Control+Phy & $5 \%$ WB +Phy & $10 \%$ WB+Phy & $5 \%$ PCFWH & $10 \%$ PCFWH & & \\
\hline Feed intake (g/d/bird) & $108^{b}$ & $104^{\mathrm{ab}}$ & $105^{\mathrm{ab}}$ & $99.9^{a}$ & $109^{b}$ & $111^{\mathrm{b}}$ & $108^{b}$ & 2.25 & 0.022 \\
\hline Laying rate (\%) & 91.3 & 93.5 & 92.2 & 91.6 & 93.3 & 93.4 & 95.8 & 1.12 & 0.104 \\
\hline Egg mass (g/d/bird) & $52.2^{\mathrm{a}}$ & $52.8^{\mathrm{ab}}$ & $52.5^{\mathrm{ab}}$ & $51.94^{\mathrm{a}}$ & $55.1^{b}$ & $54.5^{\mathrm{ab}}$ & $55.0^{b}$ & 0.85 & 0.025 \\
\hline FCR (\%) & 2.06 & 1.97 & 2.00 & 1.92 & 1.98 & 2.03 & 1.98 & 0.03 & 0.063 \\
\hline
\end{tabular}

Each value represents the mean eight replicates from 1 to $12 \mathrm{wk}$.

WB, wheat bran; Phy, WB added with phytase; PCFWH, fermented WB supplemented with molasses and phytase; SEM, standard error of the mean; FCR, feed conversion ratio.

1) Control, basal diet; 10\% WB, diet with 10\% WB; Control+Phy, basal diet supplemented with 250 unit/kg phytase; 5\% WB+Phy, diet with 5\% WB and 250 unit/kg phytase; 10\% WB+Phy, diet with 10\% WB and 250 unit/kg phytase; 5\% PCFWH, diet with 5\% PCFWH and 125 unit/kg phytase; 10\% PCFWH, diet with $10 \%$ PCFWH.

$a, b$ Means with in the same row with different letters are significantly different $(p<0.05)$.

Table 4. Effects of experimental diets on the egg quality from 1 to $12 \mathrm{wk}$

\begin{tabular}{|c|c|c|c|c|c|c|c|c|c|}
\hline \multirow{2}{*}{ Items } & \multicolumn{7}{|c|}{ Experimental diets ${ }^{1)}$} & \multirow{2}{*}{ SEM } & \multirow{2}{*}{ p-value } \\
\hline & Control & $10 \% W B$ & Control +Phy & $5 \% W B+P h y$ & $10 \% W B+P h y$ & 5\% PCFWH & $10 \%$ PCFWH & & \\
\hline Egg weight (g) & $56.3^{\mathrm{a}}$ & $56.9^{a}$ & $57.0^{\mathrm{a}}$ & $57.4^{\mathrm{ab}}$ & $58.8^{c}$ & $58.6^{\mathrm{bc}}$ & $58.7^{\mathrm{bc}}$ & 0.44 & $<0.001$ \\
\hline Eggshell weight (g) & $6.55^{\mathrm{ab}}$ & $6.60^{\mathrm{bc}}$ & $6.58^{\mathrm{bc}}$ & $6.39^{a}$ & $6.75^{\mathrm{cd}}$ & $6.73^{\mathrm{bcd}}$ & $6.83^{d}$ & 0.06 & $<0.001$ \\
\hline Eggshell strength $\left(\mathrm{kg} / \mathrm{cm}^{2}\right)$ & $4.17^{\mathrm{abc}}$ & $4.15^{\mathrm{abc}}$ & $4.29^{\mathrm{bcd}}$ & $4.07^{\mathrm{ab}}$ & $4.04^{\mathrm{a}}$ & $4.36^{\mathrm{cd}}$ & $4.51^{d}$ & 0.07 & $<0.001$ \\
\hline Shell thickness (mm) & $0.36^{\mathrm{ab}}$ & $0.37^{\mathrm{bcd}}$ & $0.36^{b c}$ & $0.35^{\mathrm{a}}$ & $0.36^{b c}$ & $0.37^{\mathrm{cd}}$ & $0.37^{d}$ & 0.003 & $<0.001$ \\
\hline Yolk color & $3.85^{\mathrm{a}}$ & $4.00^{\mathrm{ab}}$ & $4.19^{b c}$ & $4.44^{c}$ & $4.29^{\mathrm{bc}}$ & $4.04^{\mathrm{ab}}$ & $3.79^{a}$ & 0.11 & 0.001 \\
\hline Haugh unit & 81.5 & 78.9 & 78.9 & 80.2 & 80.4 & 79.5 & 80.4 & 0.62 & 0.058 \\
\hline
\end{tabular}

Each value represents the mean of six replicates.

WB, wheat bran; Phy, WB added with phytase; PCFWH, fermented WB supplemented with molasses and phytase; SEM, standard error of the mean.

1) Control, basal diet; 10\% WB, diet with 10\% WB; Control+Phy, basal diet supplemented with 250 unit/kg phytase; $5 \%$ WB+Phy, diet with $5 \%$ WB and 250 unit/kg phytase; 10\% WB+Phy, diet with 10\% WB and 250 unit/kg phytase; 5\% PCFWH, diet with 5\% PCFWH and 125 unit/kg phytase; $10 \%$ PCFWH, diet with $10 \%$ PCFWH.

${ }^{a-d}$ Means with in the same row with different letters are significantly different $(p<0.05)$.

found in the eggs of $5 \% \mathrm{WB}+$ Phy. Different experimental diets did not influence the Haugh unit of tested eggs $(\mathrm{p}>0.05)$.

\section{Layer intestinal microbial population and morphology} Results of lactic acid bacteria and the Coliform population are shown in Table 5. No significant difference was found in the microbial populations of the ileum and cecum of laying hens between treatments ( $p>0.05)$. Results of intestinal morphology are illustrated in Figure 4 and Figure 5 and quantified in Table 6. There were no significant differences in villus height, crypt depth, and villus height to crypt depth ratio of both jejunum and ileum between treatments ( $p>$ $0.05)$.

Layer serum antioxidant enzymes

Results of serum SOD, CAT, and MDA contents are demon-

Table 5. Effects of experimental diets on microbial population in the ileum and cecum of laying hens

\begin{tabular}{|c|c|c|c|c|c|c|c|}
\hline \multirow{2}{*}{ Items } & \multicolumn{5}{|c|}{ Experimental diets $^{1)}$} & \multirow{2}{*}{ SEM } & \multirow{2}{*}{ p-value } \\
\hline & Control & $5 \%$ WB+Phy & $10 \%$ WB+Phy & 5\% PCFWH & $10 \%$ PCFWH & & \\
\hline \multicolumn{8}{|c|}{ Lactic acid bacteria (log CFU/g) } \\
\hline Ileum & 8.08 & 8.40 & 8.48 & 8.74 & 8.21 & 0.39 & 0.800 \\
\hline Cecum & 9.10 & 9.03 & 9.24 & 9.28 & 8.97 & 0.19 & 0.765 \\
\hline \multicolumn{8}{|c|}{ Coliform (log CFU/g) } \\
\hline Ileum & 2.90 & 3.76 & 3.37 & 3.15 & 3.00 & 0.48 & 0.809 \\
\hline Cecum & 6.33 & 6.61 & 6.12 & 7.41 & 6.82 & 0.33 & 0.103 \\
\hline
\end{tabular}

Each value represents the mean of four replicates.

WB, wheat bran; Phy, WB added with phytase; PCFWH, fermented WB supplemented with molasses and phytase; SEM, standard error of the mean; CFU, colony-forming unit.

${ }^{1)}$ Control, basal diet; 5\% WB+Phy, diet with 5\% WB and 250 unit/kg phytase; 10\% WB+Phy, diet with 10\% WB and 250 unit/kg phytase; $5 \%$ PCFWH, diet with $5 \%$ PCFWH and 125 unit/kg phytase; 10\% PCFWH, diet with 10\% PCFWH. 
(A)

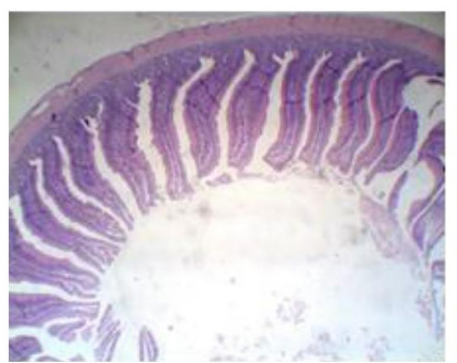

(D)

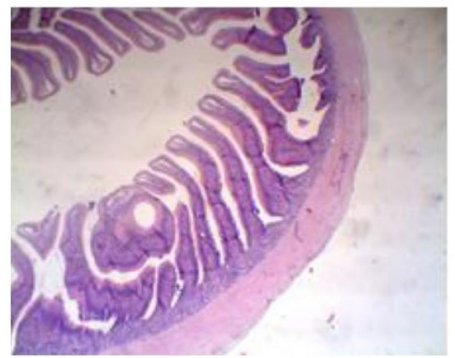

(B)

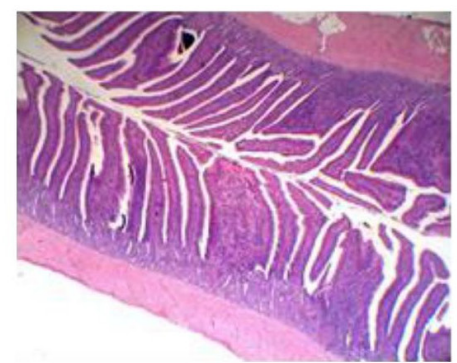

(E)

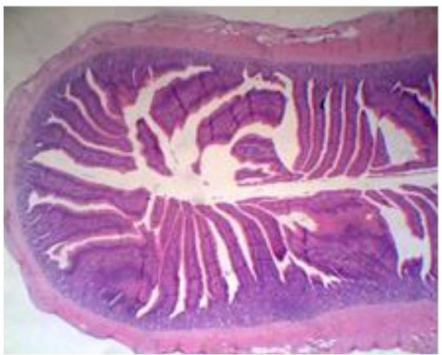

(C)

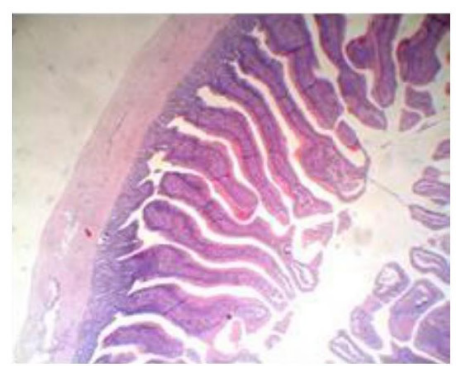

Figure 4. Jejunal morphology of laying hens fed experimental diets. (A) Control, (B) 5\% WB+Phy, (C) 10\% WB+Phy, (D) 5\% PCFWH, and (E) 10\% PCFWH. Control, basal diet; 5\% WB+Phy, diet with 5\% WB and 250 unit/kg phytase; 10\% WB+Phy, diet with $10 \%$ WB and 250 unit/kg phytase; $5 \%$ PCFWH, diet with 5\% PCFWH and 125 unit/kg phytase; 10\% PCFWH, diet with 10\% PCFWH. WB, wheat bran; Phy, WB added with phytase; PCFWH, fermented WB supplemented with molasses and phytase.

(A)

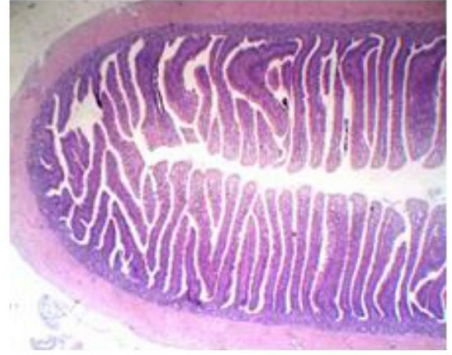

(D)

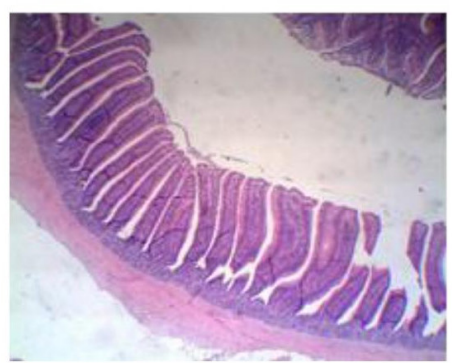

(B)

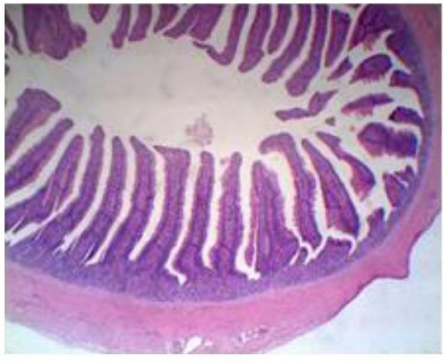

(E)

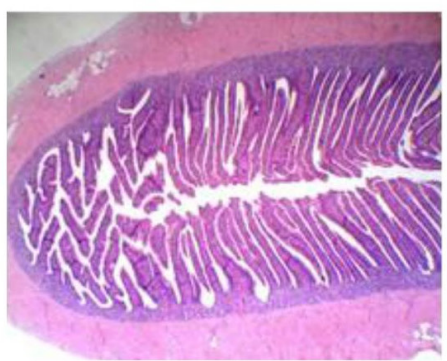

(C)

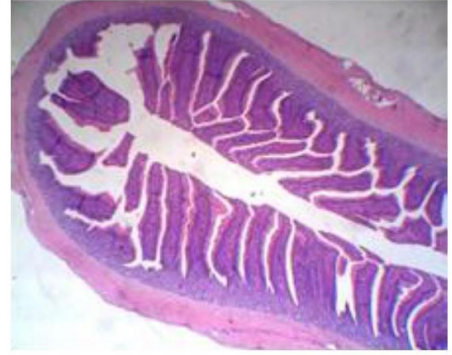

Figure 5. Ileal morphology of laying hens fed experimental diets. (A) Control, (B) 5\% WB+Phy, (C) 10\% WB+Phy, (D) 5\% PCFWH, and (E) 10\% PCFWH. Control, basal diet; $5 \%$ WB+Phy, diet with 5\% WB and 250 unit/kg phytase; $10 \%$ WB+Phy, diet with 10\% WB and 250 unit/kg phytase; $5 \%$ PCFWH, diet with 5\% PCFWH and 125 unit/kg phytase; 10\% PCFWH, diet with 10\% PCFWH. WB, wheat bran; Phy, WB added with phytase; PCFWH, fermented WB supplemented with molasses and phytase.

strated in Table 7. Experimental diets did not influence the serum MDA content ( $p>0.05)$. The 10\% PCFWH treatment resulted in significantly higher serum SOD activity than other groups except for $10 \% \mathrm{WB}+$ Phy. The highest serum CAT was also observed $10 \%$ PCFWH $(\mathrm{p}<0.05)$, while there was no significant difference between 5\% PCFWH and 10\% PCFWH. 
Table 6. Effect of experimental diets on the intestinal morphology of laying hens

\begin{tabular}{|c|c|c|c|c|c|c|c|}
\hline \multirow{2}{*}{ Items } & \multicolumn{5}{|c|}{ Experimental diets $^{1)}$} & \multirow{2}{*}{ SEM } & \multirow{2}{*}{ p-value } \\
\hline & Control & $5 \%$ WB+Phy & $10 \%$ WB+Phy & 5\% PCFWH & $10 \%$ PCFWH & & \\
\hline \multicolumn{8}{|l|}{ Jejunum } \\
\hline Villus height $(\mu \mathrm{m})$ & 1,168 & 1,139 & 1,124 & 1,011 & 1,054 & 80.6 & 0.641 \\
\hline Crypt depth ( $\mu \mathrm{m})$ & 162 & 170 & 166 & 145 & 134 & 11.2 & 0.161 \\
\hline Villus height/crypt depth & 7.25 & 6.70 & 6.82 & 7.08 & 7.87 & 0.43 & 0.366 \\
\hline \multicolumn{8}{|l|}{ lleum } \\
\hline Villus height ( $\mu \mathrm{m})$ & 888 & 876 & 884 & 821 & 758 & 46.5 & 0.269 \\
\hline Crypt depth $(\mu \mathrm{m})$ & 123 & 143 & 137 & 127 & 123 & 10.5 & 0.612 \\
\hline Villus height/crypt depth & 7.28 & 6.29 & 6.54 & 6.50 & 6.23 & 0.48 & 0.556 \\
\hline
\end{tabular}

Each value represents the mean of four replicates.

WB, wheat bran; Phy, WB added with phytase; PCFWH, fermented WB supplemented with molasses and phytase; SEM, standard error of the mean.

1) Control, basal diet; $5 \%$ WB+Phy, diet with 5\% WB and 250 unit/kg phytase; 10\% WB+Phy, diet with 10\% WB and 250 unit/kg phytase; $5 \%$ PCFWH, diet with $5 \%$ PCFWH and 125 unit/kg phytase; 10\% PCFWH, diet with 10\% PCFWH.

Table 7. Effect of experimental diets on the serum antioxidant enzyme activities and malondialdehyde content of laying hens

\begin{tabular}{|c|c|c|c|c|c|c|c|}
\hline \multirow{2}{*}{ Items } & \multicolumn{5}{|c|}{ Experimental diets ${ }^{1)}$} & \multirow{2}{*}{ SEM } & \multirow{2}{*}{ p-value } \\
\hline & Control & 5\%WB+Phy & $10 \%$ WB +Phy & $5 \%$ PCFWH & $10 \%$ PCFWH & & \\
\hline $\mathrm{MDA}(\mu \mathrm{M})$ & 55.2 & 61.1 & 56.7 & 64.4 & 62.3 & 3.55 & 0.336 \\
\hline $\mathrm{SOD}(\mathrm{U} / \mathrm{mL})$ & $40.8^{a}$ & $39.2^{\mathrm{a}}$ & $42.0^{\mathrm{ab}}$ & $39.4^{a}$ & $44.9^{\mathrm{b}}$ & 1.01 & 0.003 \\
\hline CAT $(\mathrm{nmol} / \mathrm{min} / \mathrm{mL})$ & $79.7^{\mathrm{a}}$ & $75.2^{\mathrm{a}}$ & $79.4^{\mathrm{a}}$ & $108^{\mathrm{ab}}$ & $157^{b}$ & 23.5 & 0.022 \\
\hline
\end{tabular}

Each value represents the mean of six replicates.

WB, wheat bran; Phy, WB added with phytase; PCFWH, fermented WB supplemented with molasses and phytase; SEM, standard error of the mean; MDA, malondialdehyde; SOD, superoxidase dismutase; CAT, catalase.

${ }^{1)}$ Control, basal diet; 5\% WB+Phy, diet with 5\% WB and 250 unit/kg phytase; 10\% WB+Phy, diet with 10\% WB and 250 unit/kg phytase; $5 \%$ PCFWH, diet with $5 \%$ PCFWH and 125 unit/kg phytase; $10 \%$ PCFWH, diet with 10\% PCFWH.

$a, b$ Means with in the same row with different letters are significantly different $(p<0.05)$.

\section{Layer excreta phosphorus contents}

Results of excreta phosphorus contents were in Table 8. The phosphorus content in the excreta of control group was significantly higher than other treatments $(\mathrm{p}<0.05)$. There was no significant difference between $10 \% \mathrm{WB}$, control+Phy, $5 \%$ $\mathrm{WB}+\mathrm{Phy}, 10 \% \mathrm{WB}+\mathrm{Phy}$, and 10\% PCFWH ( $>0.05)$. However, the excreta phosphorus content of 5\% PCFWH was higher than that in $10 \%$ PCFWH $(\mathrm{p}<0.05)$.

\section{DISCUSSION}

Okot-Kotber et al [17] reveal that the Phy activities in WB varied according to the species. Normally, the Phy contained in WB is about 0.92 to 3.12 Phy unit/gram. However, they also indicate that under $60^{\circ} \mathrm{C}$, the Phy activities in $\mathrm{WB}$ would decrease by about $80 \%$ within $1 \mathrm{~h}$. Therefore, it is suggested that the difference between the results of Phy activities in WB between previous research and our research might be due to the different processing procedures. Accordingly, it is estimated that there are an extra 20 to 60 Phy unit/kg in the $10 \%$ WB supplement group and an extra 10 to 30 Phy unit/kg in the 5\% WB supplement group. Co-inoculation of microorganisms and Phys has been reported, and results showed that fungal fermentation combined with Phy addition was a feasible way to elevate inorganic phosphorus in substrates [10]. Although there is high content of total phosphorus in

Table 8. Effect of experimental diets on the excreta P contents

\begin{tabular}{|c|c|c|c|c|c|c|c|c|c|}
\hline \multirow{2}{*}{ Item } & \multicolumn{7}{|c|}{ Experimental diets ${ }^{1)}$} & \multirow{2}{*}{ SEM } & \multirow{2}{*}{ p-valu } \\
\hline & Control & $10 \%$ WB & Control +Phy & 5\% WB +Phy & $10 \%$ WB +Phy & 5\% PCFWH & $10 \%$ PCFWH & & \\
\hline Excreta P (\%) & $1.79^{\mathrm{a}}$ & $0.98^{\mathrm{bc}}$ & $1.16^{\mathrm{bc}}$ & $0.89^{\mathrm{bc}}$ & $1.08^{\mathrm{bc}}$ & $1.26^{b}$ & $0.74^{\mathrm{c}}$ & 0.14 & 0.002 \\
\hline
\end{tabular}

Each value represents the mean of four replicates.

WB, wheat bran; Phy, WB added with phytase; PCFWH, fermented WB supplemented with molasses and phytase; SEM, standard error of the mean.

1) Control, basal diet; 10\% WB, diet with 10\% WB; Control+Phy, basal diet supplemented with 250 unit/kg phytase; $5 \%$ WB+Phy, diet with 5\% WB and 250 unit/kg phytase; $10 \%$ WB+Phy, diet with 10\% WB and 250 unit/kg phytase; 5\% PCFWH, diet with 5\% PCFWH and 125 unit/kg phytase; $10 \%$ PCFWH, diet with $10 \%$ PCFWH.

${ }^{a-c}$ Means with in the same row with different letters are significantly different $(p<0.05)$. 
$\mathrm{WB}$, inorganic phosphorus in $\mathrm{WB}$ was rarely released during the $3 \mathrm{~h}$ extraction period. In contrast, A. oryzae fermentation combined with Phy addition released a higher level of inorganic phosphorus than either wheat bean treated with either Phys or A. oryzae starter culture. The Phy activity was not detectable in A. oryzae fermented materials, while more inorganic phosphorus was released after A. oryzae fermentation. Chuang et al [1] reveals that co-fermentation of probiotics and Phy can improve the inorganic phosphorus release amount because of the phytate released from complex fiber, which had been degraded by probiotics enzymes. According to the above results, the PCFWH was used in the following analysis and animal trial.

In the PCFWH treatment, the CP content increased by $8.3 \%$, and NDF decreased $4.6 \%$ on the DM basis. Similar results were found in A. oryzae fermented cassava pulp where the CP content increased $9.8 \%$ and crude fiber content decreased $4 \%$ compared with non-fermented cassava pulp [18]. High spore counts, protease, and xylanase activities were also found after fermentation. It was pointed out that the content of free and linked ferulic acid in WB was 5 to 15 $\mathrm{mg} / \mathrm{g}$ [19]. In the present study, the WB was extracted with deionized water, and the content of ferulic acid was only 29.0 $\mu \mathrm{g} / \mathrm{g}$. After fungal fermentation, it was enhanced to $127 \mu \mathrm{g} / \mathrm{g}$ (Table 2). During the process of fermentation, ferulic acid was released by the actions of endoxylanases and feruloyl esterases. The higher free ferulic acid content in the substrate indicated that more of the arabinoxylan structure was degraded. Accordingly, the xylooligosaccharides, as well as Dxylose contents, were increased after fermentation (Table 2). The kojic acid, the major metabolite secreted by A. oryzae, is known to inhibit the activity of tyrosinase. Owing to this effect, it was generally applied in cosmetics as a skin-whitening agent. It was also used for food preservation since it prevented enzymatic browning [20]. Moreover, it possesses an antioxidant as well as an immunomodulatory effect [21]. In the present study, the tyrosinase inhibition rate was detected after fermentation, proving that kojic acid might be secreted in PCFWH (Table 2). The PCFWH exerted tremendous antioxidant activities (Figure 3). The antioxidant capacity was related to the phenol content of materials. During the fermentation process, A. oryzae secreted proteases that degraded proteins into small peptides and amino acids, among which tyrosine has a phenolic OH-group. Secreted xylanases destroyed the arabinoxylan structure of WB and released ferulic acid as well as FOs that also displayed antioxidant properties [1]. Moreover, glucose and D-xylose in the substrate was utilized for kojic acid synthesis, indicated by the tyrosinase inhibition activity in PCFWH. All these factors contributed to the antioxidant capacity of PCFWH.

In animal trials, WB and PCFWH were incorporated into the corn-soybean diet of laying hens and broilers chickens
$[22,23]$. Results demonstrated that hens on $5 \% \mathrm{WB}+$ Phy treatment displayed the lowest feed intake. Hens in the $10 \% \mathrm{WB}+$ Phy and 10\% PCFWH group produced higher egg masses, but $10 \%$ WB did not, compared to other treatments. However, there was no significant difference in FCR and laying rate between treatments. The WB is a by-product during the processing of wheat. It contains a high content of arabinoxylans that is scarcely degraded by digestive enzymes of monostomach animals. Therefore, the amount of WB included in the diet was limited. Comparative experiments regarding the effect of WB and fermented WB incorporated in the diet on broiler's performance have been extensively studied, and the results indicated that broilers could endure 10\% WB in the corn-soybean meal diet without displaying a decrease in performance in some experiments $[24,25]$, however in other experiments performance was negatively affected [22, 23]. In laying hens, incorporation of $5 \%$ and $10 \% \mathrm{WB}$ in maize-soybean meal diet did not harm the performance and production, while FCR was improved [26]. The 10\% WB in the diet improved egg mass while 5\% WB did not [27]. Moreover, $10 \% \mathrm{WB}$ and Phy in the diet could replace inorganic phosphorus of layers' diet while not exerting a negative influence on the performance and production [26]. It is well known that Phy addition can increase the phosphorus release amount from phytate thereby enhancing the phosphorus and amino acid utilization [1]. The increase of nutrient and mineral utilized efficiency would further improve the product performance of layers. These may explain why better egg mass was found in 10\% WB+Phy and $10 \%$ PCFWH, but not in $10 \% \mathrm{WB}$ in the present study. Saki et al [27] also pointed out that $10 \% \mathrm{WB}$ in the diet did not influence feed intake, egg mass, laying rate, and FCR.

Treatments of 10\% WB+Phy, 5\% PCFWH, and 10\% PCFWH increased egg weights compared with treatments of control, 10\% WB, and control+Phy. Moreover, 10\% PCFWH treatment led to the highest eggshell weight, eggshell strength, and shell thickness. It is known that egg quality is correlated to the phenolic compounds and/or flavonoids in the diets $[16,28]$. Yolk color is a determinative factor that impacted the preference of consumers. Yolk color is related to the xanthophyll pigments, such as carotenoids, in the diet. Lightest yolk color was observed in eggs from control group and 10\% PCFWH, while the discrepancy of color score was not large (3.79 vs 4.44). Carotenoids are extensively present in legumes, such as soybean and corn [29]. In order to incorporate WB and PCFWH into diets and equal the $\mathrm{CP}$ and metabolizable energy of each diet, formulas for different treatments varied, so the carotenoids contents also differed depending on the amounts of different legumes used in diets. Unequal contents of carotenoids between treatments explained why the yolk color of different treatments varied. The Haugh unit, a parameter of egg protein quality, was determined by the 
height of thick albumen and egg weight. In the present study, there was no significant difference in the Haugh units between treatments. This is consistent with the previous report that providing A. oryzae culture did not change the Haugh unit [30].

Xylooligosaccharides, a kind of prebiotic, has been reported to increase bifidobacteria and total anaerobes in cecum content of rats when $5 \%$ xylooligosaccharides was in the diet [31]. A similar result was also seen in mice when $10 \%$ xylooligosaccharides was supplemented to the diet [1]. In PCFWH, xylobiose and xylotriose content was 3.78 and $14.0 \mathrm{mg} / \mathrm{g}$, respectively. However, both diets containing $5 \%$ or $10 \%$ PCFWH did not influence the microbial population of lactic acid bacteria or coliforms in the ileum and cecum. Relatively low content of xylooligosaccharides in fermented products compared to xylooligosaccharides produced by microbial xylanases might be the reason why prebiotic properties were not observed in $5 \%$ or $10 \%$ PCFWH treatments.

The intestinal morphology is related to dietary fiber and gut health. A possible mechanism is that viscous digesta caused by dietary fiber may lead to apoptosis of villus cells, promote crypt cell proliferation, and consequently increase the villus height to crypt depth ratio [1]. It is noted that many factors, including the type of dietary fiber, ingestion period, animal species, and age, also affect intestinal morphology. In the present study, different experimental diets did not change the jejunal and ileal morphology. In contrast, $10 \%$ rapeseed meal in broilers' diet decreased villus height and villus height to crypt depth ratio of jejunum and ileum, while $10 \%$ fermented rapeseed meal improved intestinal morphology [32]. Accordingly, the older age and more mature development of intestinal mucosa of laying hens compared to broilers may explain why intestinal morphology was rarely affected by the composition of diet.

Serum enzyme activities and MDA content were correlated to the oxidative status of animals. Environmental stressors, including high temperature, pathogens, harmful gas and enhanced oxidative pressure lead to production of free radicals and damage to the health [21]. Therefore, antioxidant feedstuff or feed additives in the diet may improve oxidative status. In the present study, free ferulic acid was released, and antioxidant capacity in vitro was elevated in PCFWH. Previous studies also indicated that FOs were produced in Aureobasidium pullulans fermented WB, and this fermented material improved serum MDA content of S180 tumor-bearing mice [8]. In the present study, the $10 \%$ PCFWH treatment elevated serum SOD, CAT activities, indicating that the oxidative status of hens was improved.

In SSF of WB, Phy was added with A. oryzae together to promote the release of inorganic phosphorus. In the excreta, lowest phosphorus content was seen in 10\% PCFWH, but there were no significant differences between $10 \% \mathrm{WB}$, control
+Phy, 5\% WB+Phy, 10\% WB+Phy, and 10\% PCFWH. The $10 \%$ WB group without Phy supplementation also reduced excreta phosphorus content compared to the control group, indicating that the utilization of phosphorus in the diet increased because of intrinsic Phy content [33]. It was consistent with the previous report that $10 \% \mathrm{WB}$ in the diet increased the concentration of serum inorganic phosphorus [26]. It was also demonstrated that the replacement of soybean meal with A. oryzae FSBM significantly increased serum total phosphorus content [11]. According to the result, the strategy of the combination of Phy and fungal fermentation has the potential for the reduction of phosphorus in the excreta.

\section{CONCLUSION}

Large amounts of metabolites are present in PCFWH, including protease, xylanase, ferulic acid, xylooligosaccharides, and tyrosinase inhibition activity. Extractable phosphorus was also enhanced in vitro. The $\mathrm{CP}$ content was increased and NDF content reduced in PCFWH treatment. Furthermore, egg quality, serum SOD and CAT level, and excreta phosphorus content were improved in birds fed diet with $10 \%$ PCFWH.

\section{CONFLICT OF INTEREST}

We certify that there is no conflict of interest with any financial organization regarding the material discussed in the manuscript.

\section{ACKNOWLEDGMENTS}

The authors thank the Ministry of Science and Technology (109-2313-B-005 -008-MY3) and the iEGG and Animal Biotechnology Center from The Feature Areas Research Center Program within the framework of the Higher Education Sprout Project by the Ministry of Education (MOE) in Taiwan for supporting this study.

\section{REFERENCES}

1. Chuang WY, Lin WC, Hsieh YC, Huang CM, Chang SC, Lee TT. Evaluation of the combined use of Saccharomyces cerevisiae and Aspergillus oryzae with phytase fermentation products on growth, inflammatory, and intestinal morphology in broilers. Animals 2019;9:1051. https://doi.org/10.3390/ ani9121051

2. Nahm KH, Carlson CW. Effects of cellulase from Trichoderma viride on nutrient utilization by broilers. Poult Sci 1985;64: 1536-40. https://doi.org/10.3382/ps.0641536

3. Zhenping S, Wenting L, Ruikui Y, et al. Effect of a straw-derived xylooligosaccharide on broiler growth performance, endocrine 
metabolism, and immune response. Can J Vet Res 2013;77: 105-9.

4. De Maesschalck C, Eeckhaut V, Maertens L, et al. Effects of xylo-oligosaccharides on broiler chicken performance and microbiota. Appl Environ Microbiol 2015;81:5880-8. https:// doi.org/10.1128/AEM.01616-15

5. Boz H. Ferulic acid in cereals - a review. Czech J Food Sci 2015;33:1-7. https://doi.org/10.17221/401/2014-CJFS

6. Faulds CB, Williamson G. Release of ferulic acid from wheat bran by a ferulic acid esterase (FAE-III) from Aspergillus niger. Appl Microbiol Biotechnol 1995;43:1082-7. https:// doi.org/10.1007/BF00166929

7. Yuan X, Wang J, Yao H. Antioxidant activity of feruloylated oligosaccharides from wheat bran. Food Chem 2005;90:75964. https://doi.org/10.1016/j.foodchem.2004.05.025

8. Yu X, Zhu X, Gu Z, Lai S. Antioxidant activity in vivo and in vitro of two feruloyl oligosaccharides preparations produced from wheat bran and fermented by Aureobasidium pullulans. BioResources 2015;10:2167-76.

9. Eeckhout W, De Paepe M. Total phosphorus, phytate-phosphorus and phytase activity in plant feedstuffs. Anim Feed Sci Technol 1994;47:19-29. https://doi.org/10.1016/03778401(94)90156-2

10.Schons PF, Battestin V, Macedo GA. Fermentation and enzyme treatments for sorghum. Braz J Microbiol 2012;43:89-97. https://doi.org/10.1590/S1517-83822012000100010

11.Feng J, Liu X, Xu ZR, Liu YY, Lu YP. Effects of Aspergillus oryzae 3.042 fermented soybean meal on growth performance and plasma biochemical parameters in broilers. Anim Feed Sci Technol 2007;134:235-42. https://doi.org/10.1016/j.anifeedsci. 2006.08.018

12.Feng J, Liu X, Xu ZR, Lu YP, Liu YY. The effect of Aspergillus oryzae fermented soybean meal on growth performance, digestibility of dietary components and activities of intestinal enzymes in weaned piglets. Anim Feed Sci Technol 2007;134: 295-303. https://doi.org/10.1016/j.anifeedsci.2006.10.004

13. Kim DH, Heo PS, Jang JC, Jin SS, Hong JS, Kim YY. Effect of different soybean meal type on ileal digestibility of amino acid in weaning pigs. J Anim Sci Technol 2015;57:11. https:// doi.org/10.1186/s40781-015-0041-9

14.Gyamfi MA, Yonamine M, Aniya Y. Free-radical scavenging action of medicinal herbs from Ghana: Thonningia sanguinea on experimentally-induced liver injuries. Gen Pharmacol Vascul Pharmacol 1999;32:661-7. https://doi.org/10.1016/ S0306-3623(98)00238-9

15. Arnao MB, Cano A, Hernandez-Ruiz J, Garcia-Cánovas F, Acosta M. Inhibition byL-ascorbic acid and other antioxidants of the 2,2'-azino-bis(3-ethylbenzthiazoline-6-sulfonic acid) oxidation catalyzed by peroxidase: a new approach for determining total antioxidant status of foods. Anal Biochem 1996; 236:255-61. https://doi.org/10.1006/abio.1996.0164

16.Lin WC, Lee MT, Chang SC, et al. Effects of mulberry leaves on production performance and the potential modulation of antioxidative status in laying hens. Poult Sci 2017;96:1191203. https://doi.org/10.3382/ps/pew350

17. Okot-Kotber M, Yong KJ, Bagorogoza K, Liavoga A. Phytase activity in extracts of flour and bran from wheat cultivars: enhanced extractability with $\beta$-glucanase and endo-xylanase. J Cereal Sci 2003;38:307-15. https://doi.org/10.1016/S07335210(03)00037-7

18. Khempaka S, Thongkratok R, Okrathok S, Molee W. An evaluation of cassava pulp feedstuff fermented with A. oryzae, on growth performance, nutrient digestibility and carcass quality of broilers. J Poult Sci 2014;51:71-9. https://doi.org/ 10.2141/jpsa.0130022

19. Anson NM, Hemery YM, Bast A, Haenen GRMM. Optimizing the bioactive potential of wheat bran by processing. Food Funct 2012;3:362-75. https://doi.org/10.1039/c2fo10241b

20. İyidoğan N, Bayındırlı A. Effect of L-cysteine, kojic acid and 4-hexylresorcinol combination on inhibition of enzymatic browning in Amasya apple juice. J Food Eng 2004;62:299304. https://doi.org/10.1016/S0260-8774(03)00243-7

21.Lee MT, Lin WC, Yu B, Lee TT. Antioxidant capacity of phytochemicals and their potential effects on oxidative status in animals-a review. Asian-Australas J Anim Sci 2017;30: 299-308. https://doi.org/10.5713/ajas.16.0438

22. Attia YA, Al-Khalaifah H, Abd El-Hamid HS, Al-Harthi MA, El-Shafey AA. Effect of different levels of multienzymes on immune response, blood hematology and biochemistry, antioxidants status and organs histology of broiler chicks fed standard and low-density diets. Front Vet Sci 2019;6:510. https://doi.org/10.3389/fvets.2019.00510

23. Attia YA, Al-Khalaifah H, Abd El-Hamid HS, Al-Harthi MA, El-Shafey AA. Growth performance, digestibility, intestinal morphology, carcass traits and meat quality of broilers fed marginal nutrients deficiency-diet supplemented with different levels of active yeast. Livest Sci 2020;233:103945. https:// doi.org/10.1016/j.livsci.2020.103945

24. Chu YT, Lo CT, Chang SC, Lee TT. Effects of Trichoderma fermented wheat bran on growth performance, intestinal morphology and histological findings in broiler chickens. Ital Poult Sci 2017;16:82-92. https://doi.org/10.1080/182805 1X.2016.1241133

25. Wang CC, Lin LJ, Chao YP, et al. Antioxidant molecular targets of wheat bran fermented by white rot fungi and its potential modulation of antioxidative status in broiler chickens. $\mathrm{Br}$ Poult Sci 2017;58:262-71. https://doi.org/10.1080/00071668. 2017.1280772

26. Yao JH, Han JC, Wu SY, et al. Supplemental wheat bran and microbial phytase could replace inorganic phosphorus in laying hen diets. Czech J Anim Sci 2007;52:407-13. https:// doi.org/10.17221/2321-CJAS

27.Saki AA, Atrian A, Goudarzi SM, Khodakaramian G, Yousefi A. Intestinal carbohydrase activity and sodium-glucose trans- 
porter expression in layers fed diets containing wheat and rice brans supplemented with phytase. Acta Sci 2017;39:15762. https://doi.org/10.4025/actascianimsci.v39i2.31900

28.Ting S, Yeh HS, Lien TF. Effects of supplemental levels of hesperetin and naringenin on egg quality, serum traits and antioxidant activity of laying hens. Anim Feed Sci Technol 2011;163:59-66. https://doi.org/10.1016/j.anifeedsci.2010. 10.001

29. Simonne AH, Smith M, Weaver DB, Vail T, Barnes S, Wei CI. Retention and changes of soy isoflavones and carotenoids in immature soybean seeds (edamame) during processing. J Agric Food Chem 2000;48:6061-9. https://doi.org/10.1021/ jf000247f

30. Han SW, Lee KW, Lee BD, Sung CG. Effect of feeding Aspergillus oryzae culture on fecal microflora, egg qualities, and nutrient metabolizabilities in laying hens. Asian-Australas J Anim
Sci 1999;12:417-21. https://doi.org/10.5713/ajas.1999.417 31.Campbell JM, Fahey GC, Wolf BW. Selected indigestible oligosaccharides affect large bowel mass, cecal and fecal short-chain fatty acids, $\mathrm{pH}$ and microflora in rats. J Nutr 1997;127:130-6. https://doi.org/10.1093/jn/127.1.130

32. Chiang G, Lu WQ, Piao XS, Hu JK, Gong LM, Thacker PA. Effects of feeding solid-state fermented rapeseed meal on performance, nutrient digestibility, intestinal ecology and intestinal morphology of broiler chickens. Asian-Australas J Anim Sci 2010;23:263-71. https://doi.org/10.5713/ajas.2010. 90145

33. Attia YA, Bovera F, Abd El-Hamid AE, Tag El-Din AE, AlHarthi MA, El-Shafy AS. Effect of zinc bacitracin and phytase on growth performance, nutrient digestibility, carcass and meat traits of broilers. J Anim Physiol Anim Nutr 2016;100: 485-91. https://doi.org/10.1111/jpn.12397 